system. The aim of the present study was to assess the frequency of causes of minor discrepancy between bone densities of hip and spine.

Methods In this study, from all patients referred to bone marrow densitometery centre of Loghman from September 2008 to May 2009 in order to BMD assessment due to several causes and underwent spine and hip BMD. 171 cases with minor discrepancies were enrolled and causes of discrepancies were determined.

Results The mean age of patients was $92.69 \pm 13.13$ years. $87.78 \%$ of patients were female. The causes of minor discrepancy were respectively Osteoarthritis (45.03\%), Osteoporosis (28.65\%), Aortic Calcification, Osteoarthritis Deformans, Syndesmophytes and DISH each with $2.92 \%$. These causes in female gender were Osteoarthritis (48.67\%), Osteoporosis (27.33\%), Aortic Calcification and Syndesmophytes with 3.33\%; and in male they were Osteoarthritis (38.1\%), Osteoporosis and DISH each with $19.05 \%$.

Conclusions The minor discrepancy in T-score is a common finding which can result diagnostic problems in densitometry analysis. The results of the present study show that the most common causes of minor discrepancy were Osteoarthritis, Osteoporosis, Aortic Calcification, Osteoarthritis Deformans, Syndesmophytes and DISH.

\section{A6.14 mTOR DIRECTED MESENCHYMAL TISSUE RESPONSE TO INFLAMMATION IN ARTHRITIS}

doi:10.1136/annrheumdis-2013-203220.14

1,2T Karonitsch, ${ }^{2} \mathrm{~K}$ Dalwigk, ${ }^{3} \mathrm{M}$ Glehr, ${ }^{2 B}$ Niederreiter, ${ }^{2} \mathrm{CW}$ Steiner, ${ }^{2} J S$ Smolen, ${ }^{2} \mathrm{HP}$ Kiener, 'G Superti-Furga. ${ }^{1} \mathrm{CeMM}$ Research Center for Molecular Medicine of the Austrian Academy of Sciences; 'Division of Rheumatolotgy, Department of Medicine 3, Medical University of Vienna; ${ }^{3}$ Department of Orthopaedic Surgery, Medical University of Graz

Background Accumulating evidence supports the concept that fibroblast-like synoviocytes (FLS) actively participate in the destructive, inflammatory process of rheumatoid synovitis. Thus, FLS frame a synovial microenvironment that augments and perpetuates synovial inflammation. Moreover, FLS, together with macrophages form an aggressive mass of cells ("pannus"), which invades and destroys the articular cartilage. The mechanistic target of rapamycin (mTOR) is best known for coupling energy and nutrient abundance to the execution of essential cellular processes, including cell growth and cell survival. More recent data indicate that mTOR directs the cellular response to inflammatory stimuli in cells of the immune system. It remains elusive, however, whether or not this also applies to mesenchymal cells, such as FLS in the context of rheumatoid synovitis.

Materials and Methods In order to assess mTOR activity by immunhistochemistry (IHC) as well as western blotting (WB), phosphospecific antibodies against mTOR (IHC) and mTOR substrates, including 4E-BP (IHC), AKT (WB), S6K1 (WB), and S6 (IHC) were used. To determine the functional significance of mTOR activity in FLS, Torin-1, a well defined, specific inhibitor of mTOR, was used. To establish a role for mTOR in the mesencyhmal, inflammatory tissue response, we used a previously described simplified 3-D model of the synovial tissue. IL-6 and IL- 8 levels in the supernatants of 3-D cultures were measured by ELISA.

Results mTOR, 4E-BP and S6 were found to be phosphorylated in RA synovial tissues. These activated phospho-proteins were preferentially expressed in FLS, most prominently in the hyperplasic synovial lining layer. In-vitro, TNF stimulation of FLS resulted in the phosphorylation of AKT and S6K1, indicating that TNF activates the mTOR pathway in FLS. Stimulation of the $3 \mathrm{D}$ cultures with TNF resulted in hyperplasia of the lining layer at the surface of the spheres. Strikingly, treatment with Torin-1, prevented TNF induced lining layer hyperplasia. Unexpectedly, the combined treatment of 3-D cultures with TNF and Torin-1 resulted in increased production of IL- 6 as well as IL-8 when compared to cultures that were solely exposed to TNF.

Conclusions These studies provide insight into the regulatory circuits that determine the synovial mesenchymal tissue response to inflammation and suggest a multifaceted role for mTOR in arthritis

\section{A6.15 REFRACTORY CHRONIC ERYTHEMA NODOSUM AND TREATMENT WITH ANTI TNF}

doi:10.1136/annrheumdis-2013-203220.15

J Uceda, R Hernández, L Mayordomo, JL Marenco. Rheumatology Department, Valme University Hospital, Seville, Spain

Introduction Erythema nodosum septal panniculitis without vasculitis, characterised by acute episodes of inflammatory and painful subcutaneous nodules affecting, in most cases, the lower extremities. Remission of lesions occurs within 1-6 weeks without scarring or residual atrophy. There are, however, some cases which become chronic or reoccur. In $50 \%$ of cases we find an underlying cause. Treatment of acute outbreak involves rest and NSAIDs. The chronic or recurrent cases are treated with oral potassium iodide, corticosteroids, colchicine, hydroxychloroquine or immunosuppressive agents.

Objectives Description of the cases of refractory chronic erythema nodosum and review of the literature.

Methods Selection of patients with refractory chronic erythema nodosum undergoing treatment with anti TNF in the Rheumatology unit from 2000 to 2010. Literature search using PubMed with keywords erythema nodosum and Adalimumab, Etanercept, Infliximab.

Results See table 1.

Conclusions In our sample, all cases have responded favourably to treatment with anti TNF. No adverse events were observed, except the occurrence of cutaneous psoriasis in one patients after

Abstract A6.15 Table

\begin{tabular}{|c|c|c|c|c|}
\hline Patient & 1 & 2 & 3 & 4 \\
\hline Sex & Female & Female & Male & Female \\
\hline Age & 38 & 32 & 40 & 43 \\
\hline Diagnosis & Behçet's disease & Behçet's disease & Sarcoidosis & Psoriatic arthritis \\
\hline Pre-treatment & $\begin{array}{l}\text { Prednisone } 30 \mathrm{mg} / 24 \mathrm{~h} \\
\text { Azathioprine } 100 \mathrm{mg} / 24 \mathrm{~h} \\
\text { NAID maximun dosage }\end{array}$ & $\begin{array}{l}\text { Prednisone } 30 \mathrm{mg} / 24 \mathrm{~h} \\
\text { Azathioprine } 100 \mathrm{mg} / 24 \mathrm{~h}\end{array}$ & $\begin{array}{l}\text { Prednisone } 30 \mathrm{mg} / 24 \mathrm{~h} \\
\text { Azathioprine } 100 \mathrm{mg} / 24 \mathrm{~h} \\
\text { NAID maximun dosage }\end{array}$ & $\begin{array}{l}\text { Prednisone } 30 \mathrm{mg} / 24 \mathrm{~h} \\
\text { Azathioprine } 100 \mathrm{mg} / 24 \mathrm{~h} \\
\text { NAID maximum dosage }\end{array}$ \\
\hline Anti TNF & $\begin{array}{l}\text { Infliximab } 300 \mathrm{mg} \text { every } 8 \text { weeks } \\
\text { Etanercept } 50 \mathrm{mg} \text { weekly }\end{array}$ & Infliximab 300 mg every 8 weeks & Infliximab 375 mg every 8 weeks & Infliximab 300 mg every 8 weeks \\
\hline Evolution & $\begin{array}{l}\text { Psoriasis Outbreak with infliximab. } \\
\text { Improvement of erythema nodosum with both anti TNF } \\
\text { treatments a month after start of treatment }\end{array}$ & $\begin{array}{l}\text { Principio del formulario } \\
\text { Improvement a month after start of treatment with } \\
\text { resolution in the second dose }\end{array}$ & $\begin{array}{l}\text { Asymptomatic after the first } \\
\text { infusion }\end{array}$ & $\begin{array}{l}\text { Resolution of lesions after the } \\
\text { 4th infusion of infliximab }\end{array}$ \\
\hline
\end{tabular}

